\title{
Leiomyosarcoma of the pulmonary trunk associated with pericardial effusion
}

\author{
L. G. TH I J S ${ }^{1}$, T. A . J . KR O ON, \\ and TH. M. VAN LEEUWEN \\ St. Elisabeth's Hospital, Willemstad, Curaçao (Netherlands Antilles)
}

\begin{abstract}
Thijs, L. G., Kroon, T. A. J., and van Leeuwen, Th. M. (1974). Thorax, 29, 490-494. Leiomyosarcoma of the pulmonary trunk associated with pericardial effusion. The case history of a patient with a leiomyosarcoma of the pulmonary trunk is presented. The clinical picture was dominated by unexplained shortness of breath, episodes of cough and haemoptysis, general weakness, and weight loss. Signs of a pericardial effusion and pulmonary stenosis developed a few weeks before death. Thoracotomy revealed an inoperable tumour arising from the pulmonary trunk and a large pericardial effusion. Microscopy of the tumour removed at necropsy showed a leiomyosarcoma.
\end{abstract}

Primary sarcomata of the pulmonary trunk are rare. In 1969 Wackers, van der Schoot, and Hampe collected 21 cases from the literature, including their own case, and presented a review of the reported case histories. McConnell (1970) called attention to primary neoplasms of the heart and great vessels containing bony and cartilaginous elements. He found eight patients described in the literature, three of whom had tumours located in the pulmonary artery, and reported another patient with an osteosarcoma of the pulmonary artery arising from the area of the pulmonary valves.

The patient to be presented here had a leiomyosarcoma of the pulmonary trunk complicated by a pericardial effusion.

\section{CASE REPORT}

A 48-year-old white woman visited the outpatients' department on 31 August 1971 because of a cough of two months' duration, slight shortage of breath, tiredness, palpitations, and weight loss. A week before the first examination she had developed fever with pain in the right chest and haemoptysis. Abnormal physical findings were confined to the respiratory system and consisted of an impaired percussion note and weak breath sounds at the right lung base. A chest radiograph showed a few infiltrative lesions and a small pleural effusion at the right base.

A diagnosis of bronchopneumonia associated with

'Present address: Academisch Ziekenhuis der Vrije Universiteit, de Boelelaan 1117, Amsterdam, Netherlands pleurisy was made and treatment with ampicillin was started but without improvement. The patient was therefore admitted to hospital for further evaluation on 15 September 1971. Pertinent physical findings $\stackrel{\square}{\square}$ were: blood pressure $160 / 100 \mathrm{mmHg}$, pulse 88 per $\overrightarrow{\vec{A}}$ minute regular, temperature $37 \cdot 1^{\circ} \mathrm{C}$. No pathological 윽 lymph nodes were present. Examination of the chest was essentially unchanged. At this time, however, a grade II high-pitched systolic murmur was noticed in the second and third left interspaces. The chest radiograph showed slight cardiac enlargement. At the $\frac{0}{\mathcal{N}}$ right base a few linear opacities and a small pleural $\times$ effusion were visible (Fig. 1a). Tomography, broncho- $\frac{5}{3}$ graphy, and bronchoscopy were uninformative.

Lung function tests were as follows: vital capacity 0 ? $96 \%$ normal, residual volume $32 \%$ of total lung capacity, forced expired volume in one second $80 \%$ o of vital capacity, arterial carbon dioxide pressure $40 \mathrm{mmHg}$, arterial oxygen pressure $104 \mathrm{mmHg}$, and pH $7 \cdot 41$.

The electrocardiogram showed sinus rhythm with o sporadic ventricular ectopic beats, normal mean $N$ electrical axis, and slight non-specific ST-T changes. The phonocardiogram (at 2L) demonstrated third $\omega$ and fourth heart sounds, a high-pitched pansystolic murmur, and a possible early diastolic murmur.

No clear-cut diagnosis could be made. The systolic $\frac{}{\Phi}$ murmur was interpreted as non-organic. Her cough $\stackrel{\oplus}{+}$ was treated successfully with codeine and she was 7 given digitalis. Gradually her general condition im- $\overline{0}$ proved and the palpitations disappeared. The ESR $\mathbb{D}$ had fallen from $32 \mathrm{~mm}$ on admission to $13 \mathrm{~mm}$ by $\frac{O}{\mathbb{Q}}$ October 14 when she was discharged from hospital.

At the end of November 1971 she again presented with cough, increasing shortness of breath, 8 

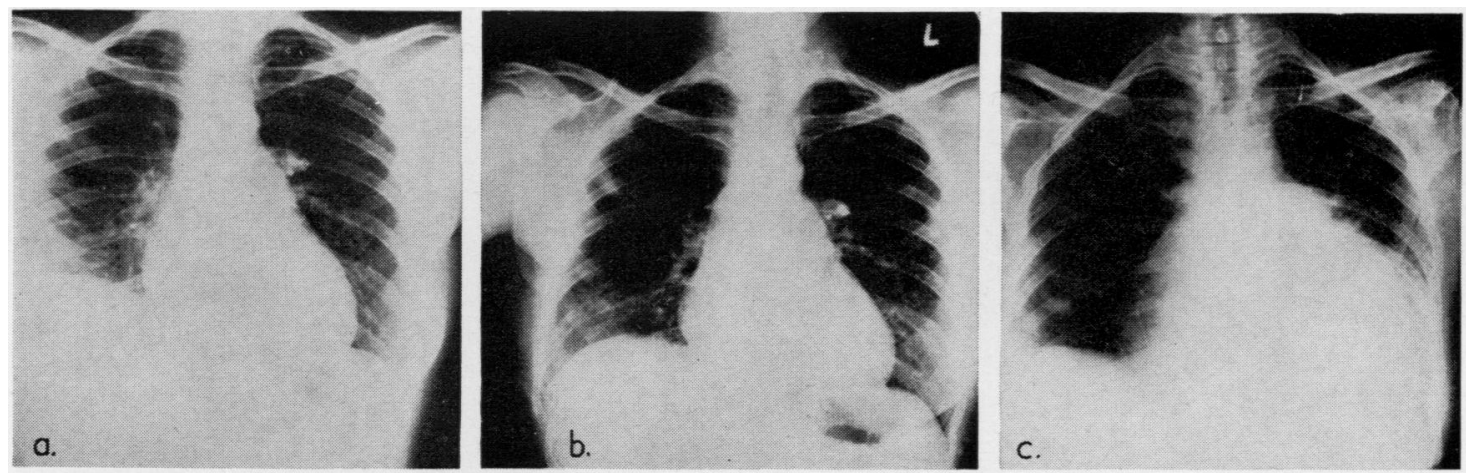

FIG. 1. Chest radiographs: (a) 17 September 1971; (b) 23 Nov ember 1971;

(c) 13 December 1971-see text.

haemoptysis, and retrosternal pain. Fluoroscopy of the chest showed both lungs to be clear and the heart was only slightly enlarged (Fig. 1b).

Early in December 1971 her general condition rapidly deteriorated. Shortness of breath was the dominating symptom, but cough and intermittent haemoptysis were still present. In addition, ankle oedema was evident and she was readmitted to hospital. Physical examination revealed an ill-looking pale woman without cyanosis but clearly dyspnoeic at rest. The blood pressure was $150 / 100 \mathrm{mmHg}$ and pulse 100 per minute with a pulsus paradoxus. The jugular veins were distended and the heart was greatly enlarged. A grade IV ejection systolic murmur was noticed at the upper left sternal border, radiating to the left shoulder and increasing on inspiration. At the lower right sternal border, a grade II pansystolic murmur was present, increasing on inspiration. The heart sounds were soft. The liver was enlarged and tender on palpation and there was pitting oedema of both legs. Laboratory tests showed slightly disturbed liver function but no other significant abnormalities. The ESR was $4 \mathrm{~mm}$. The ECG now showed sinus tachycardia with a right axis deviation, low voltage in all leads, and non-specific ST-T changes. The chest radiograph showed a greatly enlarged heart shadow (Fig. 1c).

A presumptive diagnosis of pericardial effusion with pulmonary stenosis and tricuspid regurgitation was made. On December 13 right heart catheterization was carried out. The following results were obtained: mean pressures in superior vena cava and right atrium were 15.4 and $14.8 \mathrm{mmHg}$ respectively. Right ventricular systolic and diastolic pressures were 28 and $13 \mathrm{mmHg}$ respectively. It was not possible to pass the catheter into the pulmonary trunk. Cardiac output (dye-dilution method) was $2.341 / \mathrm{min}$ and cardiac index $1.411 / \mathrm{min} / \mathrm{m}^{2}$ with a stroke volume of $19.5 \mathrm{ml}$.

A pericardial puncture was performed and serosanguinous fluid was obtained. Cytological examination of this fluid was negative. The pericardial effusion rapidly recurred and her general condition became worse. On December 16 a pericardiotomy was per- formed (Dr. J. Taams). During this procedure, after the removal of $1500 \mathrm{ml}$ serosanguinous fluid from the pericardial space, a tumour was felt on the posterior aspect of the left atrium and the great vessels. As this tumour was considered to be inoperable no further exploration was carried out. A drain was left in situ. Immediately after the operation the patient appeared well but the signs of right heart failure remained unchanged. In the evening of the same day the patient suddenly died of cardiac arrest.

NECROPSY The pericardium was reddened and fibrin deposits were evident. A tumour $(8 \times 5 \times 7$ $\mathrm{cm}$ ) was present behind the pulmonary trunk but attached to it by a broad base $(4 \times 4 \mathrm{~cm})$. The tumour extended to the left side of the left atrium and the left ventricle (Fig. 2) but remained completely within the pericardial space. When the pulmonary trunk was opened the lumen appeared to be filled with a cylindrically shaped mass (diameter approximately $3 \mathrm{~cm}$ ) which extended into the right and left pulmonary arteries. Posteriorly, this tumour was attached to the vessel wall and inferiorly to one of the pulmonary cusps. The remainder of the tumour was free in the lumen, leaving, on the anterior side, a small cleft-shaped lumen (Fig. 2b). The second pulmonary cusp was free, but below the third a small $(2.5 \times 2 \times 2.5$ $\mathrm{cm})$ solitary tumour was found.

No right ventricular hypertrophy was present (maximal wall thickness $0.5 \mathrm{~cm}$ ). Both lungs contained multiple infarcts. In the left lower lobe a small (diameter $1 \mathrm{~cm}$ ) metastasis was found. Several branches of the pulmonary artery showed evidence of thrombosis. Other organs, including the lymph nodes, were free of tumour. The liver was congested and showed a nutmeg appearance on cut surface. On microscopy (Fig. 3) the tumour was built up of bundles of spindle-shaped cells. The cells showed eosinophilic cytoplasm 
FIG. 2. (a) Anterior view of the specimen obtained at necropsy showing the tumour extending to the left side. (b) Oblique section through the tumour and the right ventricle: Ao=aorta; Pulm Tr=pulmonaryo trunk; Tu=tumour; $R V=$ right ventricle; Sept=interventricular septum.
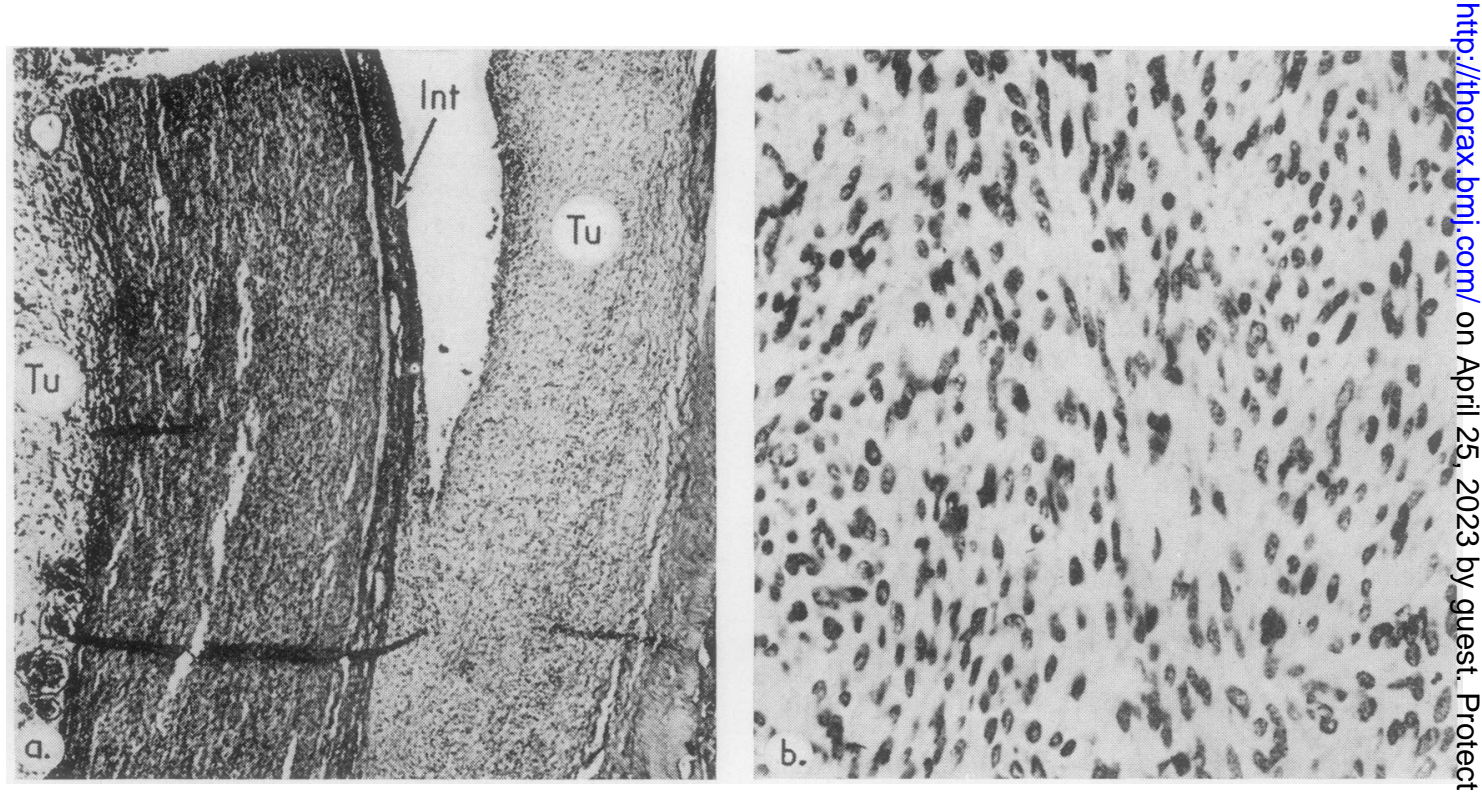

FIG. 3. Photomicrographs of the tumour. (a) Section through the pulmonary trunk showing sarcomatous $\mathbb{D}$ tissue within the lumen and outside the vessel $(\times 33): T u=$ sarcomatous tissue; Int=intima of the pulmonary trunk. (b) Histological picture of the tumour in detail $(\times 132)$. 
with longitudinal fibrils and pleomorphic nuclei containing distinct nucleoli. Mitotic figures were present but not numerous. Cytonuclear type and growth pattern were strongly suggestive of a well-differentiated leiomyosarcoma.

\section{DISCUSSION}

The present case can be classified as a leiomyosarcoma of the pulmonary trunk with intra- and extravascular extension. The origin is difficult to establish with certainty, but a few tentative conclusions can be drawn.

During her six months' illness, haemoptysis and cough may be attributed to pulmonary embolism originating from the tumour surface. Three months after the first symptoms a cardiac murmur was noticed, undoubtedly caused by the narrowing of the pulmonary trunk by tumour growth. Pericardial effusion was due to direct invasion by tumour. Presumably because of this large effusion, the tumour was not visible on the chest radiograph.

From these data we assume that the tumour originated from the tissues of the pulmonary trunk, most probably the intima, grew at first intravascularly, and later extended outside the pulmonary trunk.

In none of the reported cases of sarcoma of the pulmonary trunk has the development of a clinically detectable pericardial effusion been described. In the case of Elphinstone and Spector (1959) the pericardial sac contained $200 \mathrm{ml}$ of straw-coloured fluid, which was not diagnosed before death. Extravascular extension of the tumour has been reported several times (van der Linde, 1942; Lowell and Tuhy, 1949; Jacques and Barclay, 1960; Wolf, Dickenman, and Langston, 1960).

In most reported cases the clinical picture was dominated by unexplained progressive and mostly intractable right heart failure. However, a few cases with a different clinical picture were described. Wolf et al. (1960) reported a patient with a fibrosarcoma of the pulmonary artery with symptoms suggesting a phaeochromocytomaattacks of palpitations, sweating, and hypertension. Another unusual clinical history was reported by Green, Crevasse, and Shanklin (1964). Their patient had a fibromyxosarcoma of the pulmonary artery associated with syncope, secondary polycythaemia, and thrombocytopenia. In a few other patients syncope was a presenting symptom (Lowell and Tuhy, 1949; Hagström, 1961; McConnell, 1970). The case described by Wackers et al. (1969) concerned a leiomyosarcoma of the pulmonary trunk with a haemorrhagic tendency attributed to an intravascular coagulopathy.

Other common clinical features were cough, sometimes associated with haemoptysis, and pain in the chest related to respiration. In some cases a clinical diagnosis of pulmonary embolism was made (Elphinstone and Spector, 1959). Lung infarction was often found at necropsy (Elphinstone and Spector, 1959; Hagström, 1961; Ali and Lee, 1964) and sometimes a thrombus was located on the tumour in the pulmonary trunk (Lowell and Tuhy, 1949; Moegen, 1951; Wolf et al., 1960). Frequently the patient complained of pain in the retrosternal region and upper abdominal discomfort. Other symptoms included palpitations, fatigue, weakness, fever, and weight loss.

The histological pattern of the sarcomatous tissue varies and has been described as fibrosarcoma, leiomyosarcoma, spindle-cell sarcoma, rhabdomyosarcoma, malignant mesenchymoma, fibromyxosarcoma or anaplastic sarcoma. In the same tumour different histological types may be present (Moegen, 1951; Hagström, 1961; McConnell, 1970). McConnell (1970) postulates that chondro- and osteosarcoma arise as a fibrosarcoma and then undergo metaplasia into specific mesenchymal tissue. Secondary deposits in the lungs and direct invasion of the mediastinum are of ten seen, but metastases outside the thorax are rarely encountered (Elphinstone and Spector, 1959).

A pulmonary trunk tumour is usually not recognized during life, but one patient (Jacques and Barclay, 1960) underwent pneumonectomy because of a preoperative diagnosis of lung tumour, and the diagnosis of anaplastic sarcoma was made on histological examination. As already mentioned, McConnell (1970) described a patient with an osteosarcoma, who underwent operation and died 51 months later.

What signs may lead to the diagnosis of pulmonary artery tumour during life? The abovementioned clinical symptoms and intractable right heart failure may raise suspicion. On examination a systolic murmur is often found, and several authors stress the presence of a split-second heart sound (Elphinstone and Spector, 1959; McConnell, 1970). The ECG invariably shows right axis deviation and often signs of right ventricular hypertrophy (Lowell and Tuhy, 1949; Moegen, 1951; Wolf et al., 1960; Green et al., 1964). The chest radiograph may reveal the shadow of a tumour and cardiac enlargement due to right ventricular hypertrophy. An 
important feature may be the absence of peripheral vascular markings on the affected side (Elphinstone and Spector, 1959; Jacques and Barclay, 1960). Laboratory investigations are non-contributory, but right heart catheterization and angiocardiography may lead to early diagnosis.

\section{REFERENCES}

Ali, M. Y. and Lee, G. S. (1964). Sarcoma of the pulmonary artery. Cancer, 17, 1220.

Elphinstone, R. H. and Spector, R. G. (1959). Sarcoma of the pulmonary artery. Thorax, 14, 333.

Green, J. R., Crevasse, L. E., and Shanklin, D. R. (1964). Fibromyxosarcoma of the pulmonary artery associated with syncope, intractable heart failure, polycythemia and thrombocytopenia. American Journal of Cardiology, 13, 547.

Hagström, L. (1961). Malignant mesenchymoma in the pulmonary artery and right ventricle. Acta Pathologica et Microbiologica Scandinavica, 51, 87.

Jacques, J. E. and Barclay, R. (1960). The solid sarcomatous pulmonary artery. British Journal of Diseases of the Chest, 54, 217.
Linde, H. M. van der (1942). Sarcoom van de long slagader. Nederlands Tijdschrift voor Genees? kunde, 86, 1049.

Lowell, L. M. and Tuhy, J. E. (1949). Primaryo chondrosarcoma of the lung. Journal of Thoracie Surgery, 18, 476.

McConnell, T. H. (1970). Bony and cartilaginous tumors of the heart and great vessels. Cancers 25, 611 .

Moegen, P. (1951). Über einen primären sarkoma $\vec{\circ}$ tösen Tumor der Pulmonalarterie mit aus $\vec{\omega}$ gedehnten Metastasen in der rechten Lunge Zeitschrift für Kreislaufforschung, 40, 150.

Wackers, F. J. T., van der Schoot, J. B., and Hampe J. F. (1969). Sarcoma of the pulmonary trunko associated with hemorrhagic tendency. Cancer:

23, 339.
Wolf, P. L., Dickenman, R. C., and Langston, J. D. (1960). Fibrosarcoma of the pulmonary artery응 masquerading as a pheochromocytoma. American Journal of Clinical Pathology, 34, 146.

Requests for reprints to: Dr. L. G. Thijs, Academisch Ziekenhuis der Vrije Universiteit, de Boelelaan 1117, Amsterdam, Netherlands. 